\title{
Short-term maternal psychological stress in the post-conception period in ewes affects fetal growth and gestation length
}

\author{
Jennifer Smith, Drewe Ferguson, Guillermo Jauregui ${ }^{1}$, Martín Panarace ${ }^{1}$, Mariano Medina ${ }^{1}$, \\ Sigrid Lehnert ${ }^{2}$ and Jonathan R Hill \\ CSIRO Livestock Industries, FD McMaster Laboratory, Armidale, New South Wales 2350, Australia, ${ }^{1}$ Goyaike SAACI y \\ F Biotecnología Animal, Carmen de Areco, CP 6725, Buenos Aires, Argentina and ${ }^{2}$ CSIRO Livestock Industries \\ Queensland Biotechnology Precinct, St Lucia, Queensland 4067, Australia
}

Correspondence should be addressed to J R Hill who is now at the University of Queensland, St Lucia, 4072 Queensland, Australia; Email: jonathan.hill@uq.edu.au

\begin{abstract}
Fetal development can be influenced by maternal environment in the peri-conceptional period. This study investigated the effect of maternal feed intake and psychological stress within the first 6 days after conception on embryo development and fetal growth. Superovulated ewes $(n=40)$ were artificially inseminated with semen from one ram. Ewes were then divided into four groups ( $n=10)$ : group 1 (control) was fed at maintenance level, group 2 (high) at $2 \times$ maintenance, and group 3 (low) at 0.5 $\times$ maintenance on days 2-6 after conception. Group 4 (stress) was fed at maintenance level and then an intense physical and psychological stress challenge was applied for $\mathbf{1}$ h only on days $\mathbf{2}$ and 3 after conception. Embryos were recovered at day 6. A total of 113 transferable grade embryos were transferred singly into synchronized untreated recipients, while the remaining embryos $(n=165)$ were fixed and stained for cell counts. Post-conception maternal stress or feed intake did not alter the cell count or grade of day 6 embryos. Fetuses from the stress group had longer crown-rump lengths at day 30 and longer femur length at day 58. Fetuses from the stressed and high feed groups had greater abdominal circumferences at day 85 . Subsequent birth weights were not significantly different. Ewes carrying lambs from the stress treatment had shorter gestation lengths. These results show that short-term perturbations of the post-conception maternal environment have measurable effects on fetal development and gestation length.

Reproduction (2008) 136 259-265
\end{abstract}

\section{Introduction}

The maternal environment in the peri-conceptional period can impact upon fetal or placental growth, gestation length, and postnatal health (Armitage et al. 2004, Fleming et al. 2004, McMillen \& Robinson 2005, Oliver et al. 2007). This has important implications for human health. In commercial animal production, the notion that the animal's maximum production potential and health is affected by conditions during pregnancy creates an imperative to identify the critical time periods and mechanisms for fetal programming.

Nutrient-restricted diets around the time of conception in sheep have been shown to affect fetal development and physiology. Diet restriction for 2-3 weeks prior to mating resulted in altered embryo morphology and increased embryonic trophectoderm cell numbers (Abecia et al. 1997, Nolan et al. 1998). Gestation length was reduced by a week in ewes as a result of severe nutrient restriction from 1 month prior to conception through to month 2 of gestation (Bloomfield et al. 2003). More moderate feed restriction from 60 days prior to through to 7 days after conception resulted in earlier hypothalamic-pituitary adrenal axis activation in twin but not singleton pregnancies (Edwards \& McMillen 2002). Nutrient excess, via high feed intake from days 5 to 55 of gestation, reduced fetal cotyledon mass and lamb birth weight (Wallace et al. 2003). In gilts fed $2 \times$ maintenance from the day after conception for 2 weeks, higher embryonic losses were associated with lower maternal serum progesterone (Jindal et al. 1996).

Events during the week after conception have been shown to influence subsequent development, which demonstrates the sensitivity of early embryos to environmental cues. Progesterone supplementation during the first few days of pregnancy results in a significant increase in crown-rump length in ovine fetuses (Garrett et al. 1988, Kleemann et al. 1994). Increased birth weights result from in vitro culture of days 0-6 ovine embryos in the presence of serum that supplies an excess of energy substrates and growth factors (Walker et al. 1996).

These effects led us to target days $2-6$ post-conception as the period to alter the in vivo maternal environment during the time when embryonic development is progressing from cleavage stage through to blastocyst formation. Altered feed intake and imposition of a short-term psychological 
stress were used as peri-conceptional treatments as these are commonly encountered aspects of animal production and human society. We hypothesized that high cortisol levels induced by stress would increase energy substrate availability in the oviducts and alter early embryonic development. In dairy cattle, stress around the time of conception results in depressed pregnancy rates, and therefore practitioners of assisted reproductive technologies usually recommend strategies to reduce stress during this critical period (Dobson et al. 2001).

The aim of the present study was to investigate whether fetal growth and development can be altered by maternal stress and feed intake changes applied in the first week after conception. As in vitro-cultured embryos are highly sensitive to treatments during this first week, we hypothesized that in vivo embryos may be similarly affected by altering the maternal environment during this period. Measurable effects would illustrate the sensitivity of the developing embryo to perturbations in maternal environment around the time of conception and provide a model to study mechanisms and subsequent impacts on fetal development.

\section{Results}

\section{Plasma cortisol}

Changes in plasma cortisol were determined using a repeat-measures analysis. Cortisol level at $t_{0}$ (basal level) was fitted as a covariate and was not different for control and stress groups. Cortisol level of the stress group were elevated at $t_{1}$ and, although declining by $t_{2}$, remained significantly higher than controls $(P<0.001 ;$ Fig. 1$)$. Neither day of embryo transfer (ET; four levels) nor bleed day (days 2 and 3 after artificial insemination, $\mathrm{Al}$ ) were significant effects on cortisol level.

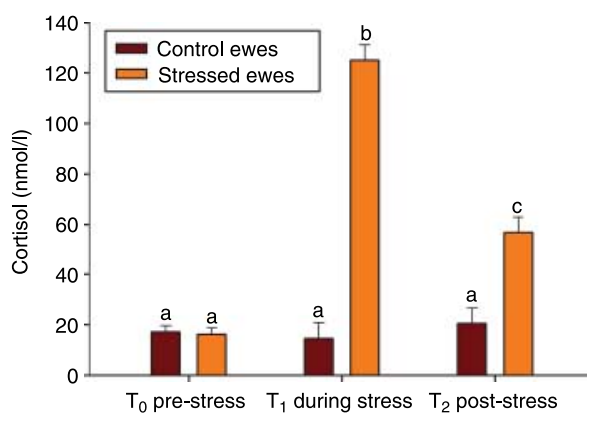

Figure 1 The severity of the stress event applied to ewes on two consecutive days (days 2 and 3 after fertilization) was illustrated by significant elevations in cortisol levels both during (time 1) and after (time 2) application of stress. Time 0 represents basal cortisol levels in treated and untreated groups. Time 1 illustrates cortisol values from samples obtained during the period of stress. Time 2 is $1 \mathrm{~h}$ later, and shows that cortisol remained elevated $15 \mathrm{~min}$ after ewes were returned to their pens, alongside control animals (values with different superscripts are significantly different at $P<0.05$ ).

\section{Embryo morphology and cell counts}

Surgical flushing of the 40 superovulated ewes yielded 343 embryos with a fertilization rate of $97.1 \%$. Of the collected embryos, $82 \%$ of embryos were graded as transferable (Table 1). Of the transferable embryos, 113 were surgically transferred singly into recipient ewes; the remainder were fixed and stained for cell counting. None of the treatments improved the proportion of transferable embryos.

Adjusted mean total cell counts of all recovered embryos and of the selected transferable quality embryos were not significantly affected by treatment (Table 1 ). There was a significant day effect on total cell count and inner cell mass (ICM)/trophectoderm ratio where the highest total cell counts were observed on the last day (day 4) of ET.

\section{Pregnancy rates}

At day 30 after $\mathrm{Al}$, the overall pregnancy rate was $61 \%$. Pregnancy rates differed significantly between the treatments, where the lowest and highest rates were observed for the high feed (44\%) and stress groups ( $80 \%$ ) respectively $(P<0.05 ;$ Fig. 2). Other treatment group contrasts were not significant. Day of transfer and recipient body weights (BWTs) were not significant effects, which indicated recipient animals were evenly spread between groups and days.

\section{Fetal development}

\section{Stress}

At day 30, crown-rump lengths of fetuses from stress ewes were $4.4 \%$ longer than controls $(P<0.05$; Table 2$)$. This difference approached significance at day $44(P=0.10)$ then at day 58 femur length was longer $(P<0.05)$. At day 85 , abdominal circumference was larger in the stress group compared with controls $(P<0.01)$. A month later (day $114)$, there was no difference between the treatment groups in femur length or abdominal circumference and this continued to day 142 . Throughout pregnancy, there were no effects of stress on fetal heart rate.

\section{Feed intake}

At days 58 and 85, fetuses from high feed ewes had larger abdominal circumferences than controls $(P<0.05$; Table 2). Heart rate at day 44 was elevated in both high and low feed intake groups and again in the high feed group at day 58 .

\section{Effect of day}

The day of ET had an effect on fetal growth up to day 44 $(P<0.05$ at day 30 and $P<0.001$ at day 44$)$. Fetuses transferred on day 4 were significantly longer than those from other ET days (e.g., at day 30 , day $4,19.8 \pm 1$ vs day 1 , $17 \pm 1.2$; day 2 , $17.8 \pm 0.7$; day $3,17 \pm 0.7)$. This 
Table 1 Number of embryos collected and embryo cell counts from superovulated donor ewes (actual embryo counts and adjusted cell count means \pm S.E.M).

\begin{tabular}{|c|c|c|c|c|c|}
\hline Embryo analysis & Control & High feed & Low feed & Stress & Total \\
\hline \multicolumn{6}{|l|}{ Embryos } \\
\hline Number embryos recovered & 80 & 96 & 68 & 99 & 343 \\
\hline Raw mean transferable grade $(\% \text { of total })^{\mathrm{a}}$ & $88 \%$ & $81 \%$ & $88 \%$ & $73 \%$ & $82 \%$ \\
\hline Adjusted mean transferable grade embryos ${ }^{b}$ & $74 \% \pm 9$ & $76 \% \pm 9$ & $88 \% \pm 9$ & $78 \% \pm 9$ & \\
\hline \multicolumn{6}{|l|}{ Cell counts } \\
\hline All embryos & $37.2 \pm 5.8$ & $46.0 \pm 5.4$ & $48.8 \pm 5.5$ & $37.6 \pm 5.5$ & 44.4 \\
\hline Transferable grade embryos & $44.8 \pm 4.7$ & $49.2 \pm 4.4$ & $52.1 \pm 4.4$ & $46.4 \pm 4.7$ & 52.6 \\
\hline Inner cell mass: trophectoderm ratio & $36.7 \pm 0.05$ & $32.7 \pm 0.05$ & $35.5 \pm 0.11$ & $36.2 \pm 0.09$ & \\
\hline \multicolumn{6}{|l|}{ Embryo survival } \\
\hline Number embryos transferred & 29 & 34 & 25 & 25 & 113 \\
\hline Ewes pregnant at day 30 & $68 \% \pm 9$ & $44 \% \pm 8$ & $55 \% \pm 11$ & $80 \% \pm 10^{*}$ & $61 \%$ \\
\hline
\end{tabular}

${ }^{*} P<0.05 .{ }^{\mathrm{a}}$ Raw $\%$ transferable grade of all embryos collected. ${ }^{\mathrm{b}}$ Adjusted mean \pm s.E.M. (donor was included as a random effect in the statistical model).

correlated with increased embryo cell number on day 4 . The strong effect of day of transfer in our experiment represented random environmental effects that persisted through pregnancy but were evened out by birth.

\section{Parturition and gestation length}

Gestation lengths for the stress fetuses were shorter ( 1.3 days) than those for controls $(P<0.05$; Table 3$)$. The effect of maternal feed intake approached significance $(P=0.065)$ for cotyledon count where the count for the high feed group trended lower than the control and low feed groups. There were no significant treatment effects on placenta weight or the weight of cotyledons as a proportion of total placenta weight. There was a significant interaction between treatment and day of ET for placenta weight and cotyledon proportion. Embryos from the control and stress groups transferred on the first 3 days were similar, but among the embryos transferred on day 4 , the stress group resulted in fetuses with much larger (almost double) placenta weight and

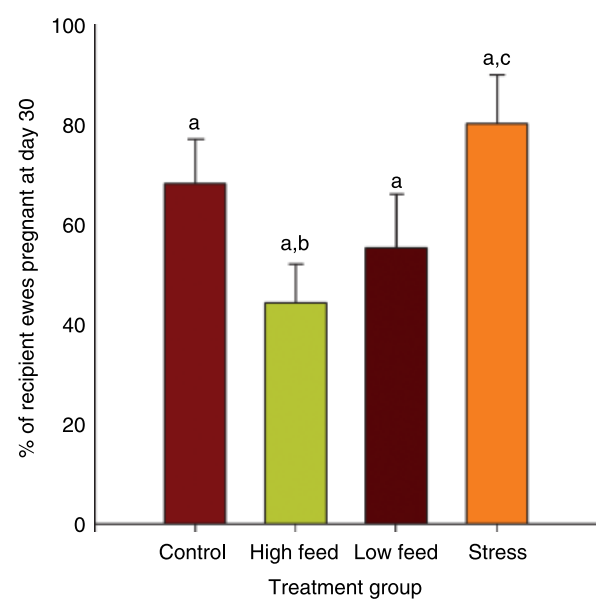

Figure 2 Pregnancy rates at day 30 were significantly lower for embryos exposed to a high feed environment compared with embryos exposed to stress after conception (values with different superscripts are significantly different at $P<0.05$ ). Contrary to our hypothesis, pregnancy rates from stressed embryos were not lower than those from controls. cotyledon proportion. Sex did not affect birth weight and there were no indications of treatment effects on birth weight (Table 3).

\section{Discussion}

By focusing on the first week after conception, we have demonstrated that brief periods of maternal stress and elevated feed intake induced measurable changes in fetal development. One hour of physical and psychological stress applied on two consecutive days during the first week following conception significantly increased fetal size during the first half of pregnancy and reduced gestation length. Increasing feed intake from days 2 to 5 after conception was found to increase fetal size at day 85 of gestation.

Fetuses with accelerated growth have resulted from exposure of embryos to a uterine environment with high substrate availability. For example, progesterone supplementation of ewes during the first 3 days after conception, as well as high maternal nutrient availability in the pre-implantation period, resulted in increased fetal growth rates (Kleemann et al. 1994, McEvoy et al. 1997). The brief stress applied to ewes in the present experiment could also have resulted in increased substrate availability to the embryo. The elevated serum cortisol levels observed in our study should have led to mobilization of energy stores and results in an increase in the levels of glucose, free fatty acids, and amino acids (Sapolsky 2002). The increase in crown-rump length observed in the stress group at day 30 could therefore be the result of increased nutrient availability, although we did not measure this in the ewes during the treatment period. Potential mechanisms for this effect include the impact of glucose concentration on the expression of glucose transporter molecules in the pre-implantation embryo as well as other membrane transporters (Pantaleon \& Kaye 1998, Jansen et al. 2006). 0.05) Subtle alterations of the biochemical environment of the pre-implantation embryo could also exert direct effects on the chromatin modification processes that take place during this period of development. 
Table 2 Assessment of treatment effects during pregnancy by ultrasonographic measurements of fetal parameters (mean \pm S.E.M.).

\begin{tabular}{|c|c|c|c|c|c|c|c|}
\hline $\begin{array}{l}\text { Fetus } \\
\text { Age }\end{array}$ & Parameter & $\begin{array}{l}\text { Control } \\
(n=19)\end{array}$ & $\begin{array}{l}\text { High feed } \\
(n=14)\end{array}$ & $\begin{array}{c}\text { Low feed } \\
(n=13)\end{array}$ & Stress $(n=20)$ & Stress effect & Feed effect \\
\hline \multirow[t]{2}{*}{30} & Heart rate & $194.5 \pm 2.6$ & $195.5 \pm 2.8$ & $194.0 \pm 3.0$ & $196.7 \pm 2.5$ & NS & NS \\
\hline & Length (crown rump) & $17.6 \pm 0.3$ & $17.5 \pm 0.3$ & $17.9 \pm 0.3$ & $18.4 \pm 0.3$ & $P<0.05$ & NS \\
\hline \multirow[t]{2}{*}{44} & Heart rate & $212.3 \pm 2.9$ & $219.8 \pm 3.1$ & $222.1 \pm 3.3$ & $218.2 \pm 2.8$ & NS & $P<0.05$ \\
\hline & Length (crown rump) & $45.8 \pm 0.7$ & $45.9 \pm 0.8$ & $46.1 \pm 0.8$ & $47.1 \pm 0.7$ & NS, $P=0.10$ & NS \\
\hline \multirow[t]{3}{*}{58} & Heart rate & $216.3 \pm 2.9$ & $222.2 \pm 3.2$ & $219.4 \pm 3.4$ & $217.3 \pm 2.9$ & NS & $P<0.05$ \\
\hline & Femur length & $8.5 \pm 0.2$ & $8.7 \pm 0.2$ & $8.5 \pm 0.2$ & $8.8 \pm 0.2$ & $P<0.05$ & NS \\
\hline & Abdominal circumference & $88.1 \pm 1.0$ & $91.1 \pm 1.0$ & $88.7 \pm 1.1$ & $90.0 \pm 1.0$ & NS & $P<0.05$ \\
\hline \multirow[t]{3}{*}{85} & Heart rate & $192.7 \pm 4.1$ & $195.1 \pm 4.4$ & $192.1 \pm 4.7$ & $191.8 \pm 4.0$ & NS & NS \\
\hline & Femur length & $24.6 \pm 0.3$ & $24.6 \pm 0.3$ & $24.0 \pm 0.4$ & $24.8 \pm 0.3$ & NS, $P=0.06$ & NS \\
\hline & Abdominal circumference & $165.1 \pm 2.2$ & $170.5 \pm 2.3$ & $164.7 \pm 2.5$ & $170.8 \pm 2.1$ & $P<0.01$ & $P<0.05$ \\
\hline \multirow[t]{3}{*}{114} & Heart rate & $167.8 \pm 3.4$ & $168.9 \pm 3.7$ & $170.8 \pm 4.0$ & $166.1 \pm 3.4$ & NS & NS \\
\hline & Femur length & $51.1 \pm 0.5$ & $50.9 \pm 0.5$ & $50.6 \pm 0.5$ & $51.0 \pm 0.5$ & NS & NS \\
\hline & Abdominal circumference & $269.5 \pm 3.6$ & $269.1 \pm 3.9$ & $267.2 \pm 4.2$ & $266.1 \pm 3.6$ & NS & NS \\
\hline \multirow[t]{3}{*}{142} & Heart rate & $132.7 \pm 4.4$ & $131.7 \pm 4.8$ & $132.9 \pm 5.4$ & $130.4 \pm 4.4$ & NS & NS \\
\hline & Femur length & $78.1 \pm 0.5$ & $78.2 \pm 0.5$ & $77.5 \pm 0.6$ & $78.4 \pm 0.5$ & NS & NS \\
\hline & Abdominal circumference & $324.5 \pm 4.8$ & $326.6 \pm 5.2$ & $325.9 \pm 5.9$ & $325.7 \pm 4.8$ & NS & NS \\
\hline
\end{tabular}

Fetal length and circumference measurements are in $\mathrm{mm}$, and heart rate in beats per minute. NS, non-significant $(P>0.05)$.

Some stressors during gestation can alter human birth weights and there is an increased risk of preterm birth in women with high levels of long-term stress (Wadhwa et al. 2001, Dole et al. 2003). Prenatal stress has been studied in rhesus monkeys but only during mid-gestation (Schneider 1992). To model human gestational stress, studies in rodents have typically focused on mid- to late gestation stressors with an outcome of behavioral and psychological changes in offspring (Kofman 2002). In one rodent study where early gestational stress (day 6) was investigated, the stressed pregnant rats gave birth to fewer females and the pups were larger by 4 weeks after birth (Mueller \& Bale 2006).

The short-term psychological stress, applied here in the early post-conception period, resulted in a significant reduction in gestation length. The reduction by 1 day was small compared with the 7-day reduction observed by Bloomfield et al. (2003). In that study, the ewes were underfed from days -60 to +30 of gestation, and the nutritional deprivation resulted in a $15 \%$ reduction in ewe BWT. The mechanism by which gestation length can be altered by an early gestational treatment is thought to be through accelerated development of the hypothalamicpituitary adrenal axis (Edwards \& McMillen 2002). This, in turn, may lead to a shift in the timing of the fetal cortisol peak that precedes parturition. It is unclear whether the effect of maternal undernutrition on the early embryo is exerted through exposure to an altered metabolic environment or to elevated glucocorticoid concentrations in response to nutritional stress. The results from the present study appear to indicate that short-term exposure of the sheep pre-implantation embryo to elevated cortisol (and adrenaline) levels led to subtle reprogramming of the hypothalamic-pituitary axis.

Embryos from high feed intake $(2 \times$ maintenance) ewes developed into fetuses with greater abdominal circumferences at day $85(P<0.05)$. Cotyledon counts tended to be lower $(P=0.065)$ in the high feed intake than maintenance or low feed groups, which is in agreement with Wallace et al. (1999) who found a small significant reduction on cotyledon count at term in ewes fed a high feed intake for the first 50 days of gestation. However, high maternal feed intake does not consistently affect placentome numbers nor fetal dimensions (Quigley et al. 2005). We did not find any effect of peri-conceptional undernutrition on fetal or placental parameters at term similar to that reported by MacLaughlin et al. (2005).

Possible mechanisms of the increased early fetal growth observed in the stress and high nutrition groups include altered imprinted gene expression, activation of universal stress response pathways in the embryo, or interference with embryo-maternal signaling. The post-conception period in sheep embryos is characterized by a prolonged period of active chromatin

Table 3 Treatment effects on birth weight and placental characteristics (mean \pm S.E.M).

\begin{tabular}{lccccc}
\hline & Control $(n=19,14)^{\mathrm{a}}$ & High feed $(n=14,12)^{\mathrm{a}}$ & Low feed $(n=11,10)^{\mathrm{a}}$ & ${\text { Stress }(n=20,16)^{\mathrm{a}}}^{\text {Stress effect }}$ \\
\hline Gestation length (days) & $154.2 \pm 0.5$ & $153.3 \pm 0.6$ & $153.5 \pm 0.6$ & $152.9 \pm 0.4$ & $\mathrm{P}<0.05$ \\
Placenta wt (g) & $341.2 \pm 33.9$ & $325.9 \pm 34.7$ & $294.1 \pm 37.7$ & $346.3 \pm 33.2$ & $\mathrm{NS}$ \\
Cotyledon number & $67.1 \pm 5.7$ & $60.0 \pm 6.0$ & $62.7 \pm 6.3$ & $66.2 \pm 5.5$ & $\mathrm{NS}$ \\
$\begin{array}{l}\text { Ratio cotyledon: } \\
\text { placenta weights }\end{array}$ & $0.26 \pm 0.03$ & $0.26 \pm 0.03$ & $0.29 \pm 0.03$ & $0.29 \pm 0.02$ & $\mathrm{NS}$ \\
Birth weight (kg) & $4.3 \pm 0.4$ & $4.6 \pm 0.4$ & $4.2 \pm 0.5$ & $4.7 \pm 0.3$ & $\mathrm{NS}$ \\
\hline
\end{tabular}

${ }^{\mathrm{a} N u m b e r}$ of observations $(n)$ are for gestation length/birth weight and placental characteristics respectively. 
de- and remethylation (Beaujean et al. 2004). This may partly explain the particular sensitivity of sheep embryos to IVF culture media (Walker et al. 1996) and to changes in the uterine environment in vivo, such as those resulting from progesterone supplementation (Kleemann et al. 1994).

We did not find any effect of treatment on embryo stage or morphological grade that could not be explained by the effect of day of ET. This contrasted with other results where high nutrition accelerated development towards the expanded blastocyst stage (Abecia et al. 1997). Our results showed that a high proportion of embryos were graded as good quality (control $88 \%$, low $88 \%$, high $81 \%$, stress $73 \%)$, whereas embryos from ewes offered high/low diets from days -10 to +4 were graded as lower quality than controls (Lozano et al. 2003).

Pregnancy rates were affected by the treatment of the donor ewes. This was anticipated; however, the significantly higher pregnancy rate in the stress group compared with the high feed group was not expected. Parr et al. (1987) showed that high feed intake on days 2-14 after mating resulted in reduced pregnancy rates in ewes and this lowered pregnancy rate was reversed by progesterone supplementation.

This study provides evidence of fetal responses to mild changes in maternal environmental stress and nutrition and provides further evidence of fetal responses to altered maternal environment. It sets the basis from which to explore the effects of psychological stress in its various manifestations on fetal development. This has implications for both livestock productivity and human health. We used a short-term stress, just $1 \mathrm{~h}$, and in future experiments we propose to investigate longer periods of stress, which are regularly encountered by livestock (e.g., storms, feed deprivation, handling stresses). In modern society, women during early pregnancy are also exposed to stressful environments and the sheep model developed here may produce relevant information to correlate with human situations.

\section{Materials and Methods}

\section{Ewe selection and preparation}

All procedures were carried out in accordance with the Australian Code of Practice for the Use of Animals for Scientific Purposes and approved by the CSIRO Livestock Industries Animal Ethics Committee. BWT and body condition score (BCS scale 1-5) of 160 Merino ewes were recorded prior to the allocation of ewes to donor or recipient groups. These measures were then repeated prior to $\mathrm{Al}$ and several times throughout pregnancy. Ewes were allowed to adjust to the pellet ration and animal house conditions for 1 week prior to estrous synchronization and allocation to treatment groups. The ration was lucerne-based commercial sheep pellets (8 MJ ME/kg, 15.5\% crude protein). Forty ewes were selected as ET donors with mean BWT of $40 \mathrm{~kg}$ and BCS of 3.0, while the remaining 120 ewes were allocated to be recipients.

Donor ewes were superovulated and inseminated as four separate day groups (10 per group). On day 2 after $\mathrm{Al}$, they were separated and allocated to the following treatment groups: (i) control - maintenance days 2-6 after conception, (ii) high feed $-2 \times$ maintenance days $2-6$ after conception, (iii) low feed $-0.5 \times$ maintenance days 2-6 after conception, and (iv) stress - maintenance days 2-6 after conception + stress on days 2 and 3 .

Ewes were distributed from each treatment group across the 4 days. Thus, on each of the four separate days, embryos were recovered from ten ewes during the morning, and then on the same afternoon the embryos were either transferred into at least 25 recipients or retained for cell counts.

\section{Feed intake and stress treatments}

In the week prior to, and after $\mathrm{Al}$, donors were fed individually in single pens. All ewes were fed at maintenance $(0.8 \mathrm{~kg} / \mathrm{d})$ in the week up to, and the day after Al. The experimental treatments commenced on day 2 post-Al. The donor ewes were returned to pasture after ET on day 6.

The stress treatment comprised a combination of physical and psychological stressors including transport from the animal pens to nearby shearing shed/sheep yards, shearing (half belly wool shorn off on each day), exposure to a sheep dog for 1 -h duration, and 10-min isolation from other sheep followed by movement back to their pens with the assistance of a dog. Blood samples ( $6 \mathrm{ml} \mathrm{K}$-EDTA vacutainers) for measurement of plasma cortisol were collected by jugular venipuncture from control and stress group ewes on the stress treatment days. These samples were collected immediately prior to commencement of the stress period $\left(t_{0}\right)$, approximately midway through the stress period $\left(t_{1}\right)$, and $15 \mathrm{~min}$ after cessation of the stress period $\left(t_{2}\right)$. The samples were collected on both days 2 and 3 . The control group ewes remained in their pens and were bled at similar times to the stress group ewes. Plasma cortisol was determined using a commercial RIA (Spectria Cortisol RIA; Orion Diagnostica, Espoo, Finland), adapted, and validated for ovine plasma (Paull et al. 2007).

\section{Superovulation, insemination, and ET}

The estrous cycles of donor and recipient ewes were synchronized using progesterone implants (EAZI_BREED CIDR Sheep and Goat Device; Pharmacia and Upjohn Pty Limited, Rydalmere, New South Wales, Australia) for 14 days. Superovulation of donor ewes was achieved by a twice daily decreasing treatment of follicle-stimulating hormone (Folltropin; Bioniche, Belleville, Canada) for 4 days concluding $24 \mathrm{~h}$ after CIDR removal. Equine chorionic gonadotropin (eCG 200 IU; Pregnecol, Bioniche) was administered i.m. the day before CIDR removal. Laparoscopic insemination was carried out $\sim 39 \mathrm{~h}$ after CIDR removal using freshly collected semen from a single sire (day 0). On day 6, embryos were recovered from the uterus under general anesthesia using ViGro Complete Flush Solution (Bioniche). Recovered embryos were washed in ViGro and then 
held in HEPES-buffered SOF embryo holding medium (Cook Embryo Holding Medium, Brisbane, Queensland, Australia) at room temperature $\left(24{ }^{\circ} \mathrm{C}\right)$ to enable grading and sorting. The embryos were held for 2-4 h prior to transfer into recipient ewes. Transfer of embryos into the uterus was via laparoscopic assistance under heavy sedation (3 mg xylazine i.m.). The embryos were randomly transferred into recipient ewes.

\section{Embryo grading and cell counts}

Embryo morphology was evaluated under a stereomicroscope for grading according to developmental stage (morula through to expanded blastocyst) and quality (1-4). Embryos were classified as transferable quality when they achieved grade 1 or 2 , and they were at the appropriate stage of development for day 6 after fertilization (compact morula or blastocyst). The embryos of transferable grade were randomly assigned to be either transferred into a recipient (single embryo per recipient) or fixed and stained for cell counting.

Total cell counts were established by equilibration of embryos in $0.5 \mathrm{mg} / \mathrm{ml}$ Hoechst 33342 for $30 \mathrm{~min}$. Compact morula, morula, and degenerate embryos were then visualized under u.v. light using a blue/green filter. Blastocysts were differentially stained to show ICM and trophectoderm cells. Differential staining was accomplished by disrupting membrane integrity on the surface trophectoderm cells with detergent (Triton X-100) together with staining by propidium iodide and Hoechst 33342 (Thouas et al. 2001). This permitted penetration of propidium iodide into the trophectoderm cells but not the ICM cells. As all cells were stained with Hoechst 33342, the ICM stained blue and the trophectoderm red. All evaluations were performed without knowledge of treatment groups.

\section{Ultrasonographic evaluation of fetuses}

Pregnancy was determined by ultrasonography on day 30 of gestation. Thereafter, fetal heart rate (beats/min) and growth measures were recorded by ultrasound scanning on days 30, $44,58,85,114$, and 142 of gestation. The operator was blind to treatment groups. On days 30 and 44, fetal assessment was performed transrectally and fetal size was assessed as crownrump length $(\mathrm{mm})$. Thereafter, scanning was transabdominal and fetal crown rump was replaced by femur length $(\mathrm{mm})$ and abdominal circumference $(\mathrm{mm})$. Each parameter was measured at least twice and the mean recorded.

\section{Parturition}

Lambing took place in indoor pens under constant supervision during the day and every $6 \mathrm{~h}$ at night. This allowed recovery of the majority of placentas and for the time of parturition to be recorded within $6 \mathrm{~h}$ of birth. Lamb records included birth date, sex, weight, surrogate dam (embryo recipient), and genetic dam (embryo donor). Intact placentas were weighed and then the cotyledons were counted, dissected off the membranes, and weighed separately from the remaining placenta.

\section{Statistical analysis}

Data were analyzed using ASReml (Gilmour et al. 2002). ANOVA was carried out to test for the main effects of maternal feed intake (control, high, low), stress (stress, unstressed), day of ET (4 days), and where appropriate, fetal sex on embryonic cell count, pregnancy rate, fetal heart rate and growth, birth weight, and placental measurements. Where appropriate, maternal BWTs were fitted as covariates and first-order interactions were included. Donor was fitted as a random effect to the cell count data. Stress and feed were retained in the final model and nonsignificant main effects and interactions iteratively removed. Data are presented as ASReml predicted means \pm S.E.M. All traits examined were tested for statistical normality and no data transformations were required.

\section{Declaration of interest}

The authors declare that there is no conflict of interest that would prejudice the impartiality of this scientific work.

\section{Funding}

This work was supported by funding from Goyaike SAACI y $\mathrm{F}$ Biotecnología Animal, Buenos Aires, Argentina, and CSIRO Livestock Industries, Brisbane, Australia.

\section{Acknowledgements}

L Piper provided valuable statistical advice; J Lea performed the cortisol assays; S Atkinson, R Davey, and K Hutton assisted with the embryo transfer; and D Niemeyer and S Belson assisted with sampling and feeding, all of which was greatly appreciated.

\section{References}

Abecia JA, Lozano JM, Forcada F \& Zarazaga L 1997 Effect of level of dietary energy and protein on embryo survival and progesterone production on day eight of pregnancy in Rasa Aragonesa ewes. Animal Reproduction Science 48 209-218.

Armitage JA, Khan IY, Taylor PD, Nathanielsz PW \& Poston L 2004 Developmental programming of the metabolic syndrome by maternal nutritional imbalance: how strong is the evidence from experimental models in mammals? Journal of Physiology 561 355-377.

Beaujean N, Hartshorne G, Cavilla J, Taylor J, Gardner J, Wilmut I, Meehan R \& Young L 2004 Non-conservation of mammalian preimplantation methylation dynamics. Current Biology 14 R266-R267.

Bloomfield FH, Oliver MH, Hawkins P, Campbell M, Phillips DJ, Gluckman PD, Challis JR \& Harding JE 2003 A periconceptional nutritional origin for noninfectious preterm birth. Science $\mathbf{3 0 0} 606$.

Dobson H, Tebble JE, Smith RF \& Ward WR 2001 Is stress really all that important? Theriogenology 55 65-73.

Dole N, Savitz DA, Hertz-Picciotto I, Siega-Riz AM, McMahon MJ \& Buekens P 2003 Maternal stress and preterm birth. American Journal of Epidemiology 157 14-24.

Edwards LJ \& McMillen IC 2002 Impact of maternal undernutrition during the periconceptional period, fetal number, and fetal sex on the development of the hypothalamo-pituitary adrenal axis in sheep during late gestation. Biology of Reproduction 66 1562-1569.

Fleming TP, Kwong WY, Porter R, Ursell E, Fesenko I, Wilkins A, Miller DJ, Watkins AJ \& Eckert JJ 2004 The embryo and its future. Biology of Reproduction 71 1046-1054. 
Garrett JE, Geisert RD, Zavy MT \& Morgan GL 1988 Evidence for maternal regulation of early conceptus growth and development in beef cattle. Journal of Reproduction and Fertility 84 437-446.

Gilmour AR, Gogel BJ, Cullis BR, Welham SJ \& Thompson R 2002 ASReml User Guide Release 1.0. Hemel Hempstead: VSN International Ltd.

Jansen S, Esmaeilpour T, Pantaleon M \& Kaye PL 2006 Glucose affects monocarboxylate cotransporter (MCT) 1 expression during mouse preimplantation development. Reproduction 131 469-479.

Jindal R, Cosgrove JR, Aherne FX \& Foxcroft GR 1996 Effect of nutrition on embryonal mortality in gilts: association with progesterone. Journal of Animal Science 74 620-624.

Kleemann DO, Walker SK \& Seamark RF 1994 Enhanced fetal growth in sheep administered progesterone during the first three days of pregnancy. Journal of Reproduction and Fertility 102 411-417.

Kofman O 2002 The role of prenatal stress in the etiology of developmental behavioural disorders. Neuroscience and Biobehavioral Reviews 26 457-470.

Lozano JM, Lonergan P, Boland MP \& O'Callaghan D 2003 Influence of nutrition on the effectiveness of superovulation programmes in ewes: effect on oocyte quality and post-fertilization development. Reproduction 125 543-553.

MacLaughlin SM, Walker SK, Roberts CT, Kleemann DO \& McMillen IC 2005 Periconceptional nutrition and the relationship between maternal body weight changes in the periconceptional period and feto-placental growth in the sheep. Journal of Physiology 565 111-124.

McEvoy TG, Robinson JJ, Aitken RP, Findlay PA \& Robertson IS 1997 Dietary excesses of urea influence the viability and metabolism of preimplantation sheep embryos and may affect fetal growth among survivors. Animal Reproduction Science 47 71-90.

McMillen IC \& Robinson JS 2005 Developmental origins of the metabolic syndrome: prediction, plasticity, and programming. Physiological Reviews 85 571-633.

Mueller BR \& Bale TL 2006 Impact of prenatal stress on long term body weight is dependent on timing and maternal sensitivity. Physiology and Behavior 88 605-614.

Nolan R, O'Callaghan D, Duby RT, Lonergan P \& Boland MP 1998 The influence of short-term nutrient changes on follicle growth and embryo production following superovulation in beef heifers. Theriogenology $\mathbf{5 0}$ 1263-1274.

Oliver MH, Jaquiery AL, Bloomfield FH \& Harding JE 2007 The effects of maternal nutrition around the time of conception on the health of the offspring. Society of Reproduction and Fertility Supplement 64 397-410.

Pantaleon M \& Kaye PL 1998 Glucose transporters in preimplantation development. Reviews of Reproduction 3 77-81.
Parr RA, Davis IF, Fairclough RJ \& Miles MA 1987 Overfeeding during early pregnancy reduces peripheral progesterone concentration and pregnancy rate in sheep. Journal of Reproduction and Fertility 80 317-320.

Paull DR, Lee C, Colditz IG, Atkinson SJ \& Fisher AD 2007 The effect of a topical anaesthetic formulation, systemic flunixin and carprofen, singly or in combination, on cortisol and behavioural responses of Merino lambs to mulesing. Australian Veterinary Journal 859.

Quigley SP, Kleemann DO, Kakar MA, Owens JA, Nattrass GS, Maddocks S \& Walker SK 2005 Myogenesis in sheep is altered by maternal feed intake during the peri-conception period. Animal Reproduction Science 87 241-251.

Sapolsky RM 2002 Endocrinology of the stress-response. In Behavioural Endocrinology, edn 2. Eds JB Becker, SM Breedlove, D Crews \& MM McCarthy. Massachusetts, USA: MIT Press.

Schneider ML 1992 Prenatal stress exposure alters postnatal behavioral expression under conditions of novelty challenge in rhesus monkey infants. Developmental Psychobiology 25 529-540.

Thouas GA, Korfiatis NA, French AJ, Jones GM \& Trounson AO 2001 Simplified technique for differential staining of inner cell mass and trophectoderm cells of mouse and bovine blastocysts. Reproductive Biomedicine Online 3 25-29.

Wadhwa PD, Culhane JF, Rauh V \& Barve SS 2001 Stress and preterm birth: neuroendocrine, immune/inflammatory, and vascular mechanisms. Maternal and Child Health Journal 5 119-125.

Walker SK, Hartwich KM \& Seamark RF 1996 The production of unusually large offspring following embryo manipulation: concepts and challenges. Theriogenology 45 111-120.

Wallace JM, Bourke DA, Aitken RP \& Cruickshank MA 1999 Switching maternal dietary intake at the end of the first trimester has profound effects on placental development and fetal growth in adolescent ewes carrying singleton fetuses. Biology of Reproduction 61 101-110.

Wallace JM, Bourke DA, Da Silva P \& Aitken RP 2003 Influence of progesterone supplementation during the first third of pregnancy on fetal and placental growth in overnourished adolescent ewes. Reproduction $126481-487$.

Received 5 September 2007

First decision 30 October 2007

Revised manuscript received 13 February 2008

Accepted 8 May 2008 